diploma, and $1 l$. for the stamp, and waits in the antechamber, until the oath is administered. It often happens that young men are exceedingly alarmed, and sometimes they faint, or sit like statues, unable to answer a single question. I asked a man the other night, "What brought him before us ?' He said at last, 'He did not know.' I believe if I had asked him his narne, he could not have told me. Such candidates retire for an hour or two to recover their faculties, if they can; and if they come in again, and look just as frightened as before, we give them leave to come up the next day of examination; or when he likes, but they seldom come up again quickly. They wait four or five months, until they have qualified themselves a little better. I think it would be just as well, if the oath of candidates were done away with.

65. The examincrs are paid whether the candidate is rejected or not; ${ }^{*}$ but if he come up again in less than six months, the Court receives no fee for this second examination. The Court of ten examiners is paid for each candidate five guineas, and one guinea is paid to each examiner for being there at the commencement of the Court, and remaining until its termination. When the whole duty is performed, it amounts to six guineas a uight for each examincr, which I suppose is paid about fifty times in the year. Now for that sum, to say nothing about getting dinner before five o'clock, I leave home before half-past five, and get back rarely much earlier than one o'clock. This amounts to a very great inconvenience. The generality of us are men who have been, or are THE MOST PROMINENT IN THE PROFESSION, + and the surgeon of a life office, who is generally not a very prominent person in his profession, gets three guineas an hour for our one guinea. I mention this, because it has been stated, that the Court of Examiners have plundered the public, *** * And most truly stated, for these very examiners all of them have voted in Council for regulations which require that the candidates who come before them should previonsly go to the hospitals, aud pay there to them (the Examiners) ten times as much for certificates, as the six guineas, which they receive per night for the examinations.

66. "Was not the museum of John Hunter given by Government to the College of Surgeons?"- "Yes, in trust for the

* True, but the whole Council lose twenty-one guineas by a rejection.

$\uparrow$ Most modest Author, Surgeon, and Examiner. public. It was first offered to the College of Physicians, who generally have more interest with Government, but they refused to have it, because it would require money to keep it up. The College of Surgeons were quite as poor, but they did not hesitate a moment in saying that they would do their utrnost to make it serviceable to the public. It cost, I thirik, 15,000l., which was paid to Mrs. Hunter, and Government awarded us 27,500l., to erect a building to contain it. There was no catalogue, or only a very imperfect one. So the Council applied to the late Sir Everard Home; and he, assisted by Mr. Clift, made out one to the best of his information, and the old papers. It consists of three large books. It has been said the College have taken no pains upon the subject; that the museum was left in a state reflecting on the governing body; that there was no catalogue in the museum. So far from this being the case, it is now shown not to be the fact. The College was, however, very dissatisfied with a slightly descriptive and almost numerical catalogue, so Mr. Clift, with his son and Mr. Owen, have since made a new catalogue, eight or nine volumes of which are before the Committee, and evcry preparation is now numbered to correspont, so that it may be found in a moment."-A very great eulogium here follows on the state of the museum. In reply to the astonishing denial which we have printed in italics, we may simply refer to the statement of Mr. Earle, one of the Council, who in The Laseser, No. 512, page 404 , said at his Hunterian oration that the preparations were covered with dust and in the utmost confusion. Here we must stop for the present.

CAEE OF

\section{RUPTURE OF THE HEART.}

\section{To the Editor of Tre LanceT.}

Sir,-I was lately called npon by a magistrate in this neighbourhool to examine the body of a man named Lehane, who died suddenly in the parish of Ballyvourney in this county, and whose death was reported to the police as having occurred under suspicious circumstances. It was stated that the deceased had received a blow from the handle of a spade across the loins, from a fellow labourer in the field where he was at work, a short time previous to his death.

Lehane had been buried in the churchyard of Ballyvourney when the report 
reached the magistrate. I accordingly went to Ballyvourney, accompanied by a magistrate and some police, and we had the body disinterred, fifty hours after death.

On examining externally, I could find no mark of violence. I then proceeded to open the different cavities. The whole of the contents of the abdomen appeared to be quite healthy, but rather exsanguincous; cven the large veins containcd but little blood. On opening the carity of the thorax, by mising the sternum with the car tilages of the ribs attached to it, I observed the perisardinm to be enormously distended. The upper or anterior surface of both lungs appcared to be quite healthy, but of a very dark ash colour.

The pericardium, when cut into, contained in its cavity about four pounds of coagulated blood, and the heart lay at its upper and posterior part, very little enlarged in size. I found a small aperture opening into the left ventricle, about two lines in diameter, and with rugged edges, through which the blood had escaped from the heart into the pericardium. This ruptured orifice was situated, about three quarters of an inch below the junction of the heart wirh the arta, and on the anterior and towards the lateral surface of the heart. I slit up the left ventricle from its apex until I arrived at the commencement of the aorta, where 1 found the semilunar valves so thickened and altered in their structure as almost completely to block up the ventriculoaortic passage, so that only a column of blood of the size of a pea could pass into the great artery.

The cavity of the left ventricle was enlarged, but its parietes were not thickened; on the contrary, at the part where the rupture took place, the wail of the ventricle had become so attenuated as to give way, when the unfortunate man made some strong bodily exertion. The mitral valves were not in the slightest degree diseased, and the right ventricle, with its valvular apparatus, was perfectly normal in structure.

The posterior part of the left lung was much engorger with blood, the right lung not so. Both lungs were emphysematous, but not to any considerable degree. The deposition of the dark carbonaceous matter in the substance of the lungs was very great, the patient being only thirty-eight years old. On opening the bronchial tibes I found traces of considerable congestive disease of those vessels, but more particularly in the larger ones. The mucous surface of these organs presented in many places a deep-red colour, and in other places approaching to a rusty brown, and they were coated with a bloody, frothy, muco-purulent matter.

The cavity of the craninm presented only three appearances. The brain and its membrancs were perfectly free from disease, but seemed rather deficient in the quantity of blood. The large sinus contained some blood, but the smaller veins scarcely any. The substance of the brain was firmer than usual, and about one ounce of serum was found in the ventricles.

There could be but one opinion as to the cause of the man's death, and I reported to the magistrate that he had died from natural causes, and the story of his being struck with a spade-handle proved to be a fiction of a malicious neighbour.

I obtained but a very imperfect history of this case from the relations of the deceascd, who were extremely igriorant and stupid people. They said that Lehane had been ailing for the last ten years, and that when he first became ill he complained of great pains all over his body; afterwards he experienced severe palpitations, and violent pain in his chest, left side, and arm, and could not sleep unless his head was quite on a level with the rest of his body. He had frequent fits of giddiness, and used to fall down " in a dead faint." He had had some medical treatment, but as the gentleman under whose care he had been had left this neighbourhood, I could not learn anything about it except that he was bled and blistered. On the day that he died he was attempting to plough, having found himself better than he had been for a long time previously; but in turning the plough, when it came to the end of a ridge, the cxertion was too great, and he fell down in the field and expired in about ten minutes after, his friends not having time to take him home alive. I regret much that 1 could not get a better history of this case, but the dissection I consider. interestirng.- $-1 \mathrm{am}$, Sir, your obedient servant,

$$
\text { Macroom, Co. Cork, May 19, } 1835 .
$$

The third part of Dr. Copland's "Dictionary of Practical Medicine" has recently been issued from the House of Messrs. Longman. It exhibits no cessation in the exercise of the admirable industry and advantageous powers of condensation which have distinguished the authorship of the preceding parts of the work. 